\title{
ELECTRONIC COMMUNITIES: A FORUM FOR SUPPORTING WOMEN PROFESSIONALS AND STUDENTS IN TECHNICAL AND SCIENTIFIC FIELDS
}

\author{
Peg Boyle Single ${ }^{1}$, Carol B. Muller ${ }^{1}$, Christine M. Cunningham ${ }^{2}$, \\ and Richard M. Single \\ ${ }^{1}$ MentorNet; ${ }^{2}$ Cornell University; ${ }^{3}$ St. Olaf College
}

In this article, we report on electronic discussion lists (e-lists) sponsored by MentorNet, the National Electronic Industrial Mentoring Network for Women in Engineering and Science. Using the Internet, the MentorNet program connects students in engineering and science with mentors working in industry. These e-lists are a feature of MentorNet's larger electronic mentoring program and were sponsored to foster the establishment of community among women engineering and science students and men and women professionals in those fields.

This research supports the hypothesis that electronic communications can be used to develop community among engineering and science students and professionals and identifies factors influencing the emergence of electronic communities (e-communities). The e-lists that emerged into self-sustaining ecommunities were focused on topic-based themes, such as balancing personal and work life, issues pertaining to women in engineering and science, and job searching. These e-communities were perceived to be safe places, embraced a diversity of opinions and experiences, and sanctioned personal and meaningful postings on the part of the participants. The e-communities maintained three to four simultaneous threaded discussions and were sustained by professionals who served as facilitators by seeding the e-lists with discussion topics.

The e-lists were sponsored to provide women students participating in MentorNet with access to groups of technical and scientific professionals. In addition to providing benefits to the students, the elists also provided the professionals with opportunities to engage in peer mentoring with other, mostly

female, technical and scientific professionals. We discuss the implications of our findings for developing e-communities and for serving the needs of women in technical and scientific fields.

\section{INTRODUCTION}

Electronic communications are providing unprecedented opportunities for supporting and connecting women in technical and scientific fields. Electronic communications, particularly personal electronic mail (email) and email-based group discussion lists, have 
characteristics that foster the development of personal relationships on-line (Rheingold, 1993; Walther, 1996). The flexible communication environment permits people sharing similar interests to interact independent of time and location constraints (Steinberg, 1992). Electronic communications allow the communicators to think about and carefully craft messages. Furthermore, self-disclosure among strangers appears to emerge more readily than in face to face communications; these benefits seem to be heightened for members of minority groups or those on the fringe of an organization (Single \& Muller, 1999b; Sproull \& Kiesler, 1992; Winter \& Huff, 1996).

Programs are capitalizing on these characteristics of electronic communications to support and increase the representation of women students in engineering and science fields, either through the provision of electronic mentoring (e-mentoring) opportunities, by using email to supplement face-to-face mentoring, or by facilitating the development of electronic communities (e-communities) (Brainard \& Ailes-Sengers, 1994; Bennett, 1997; Muller, 1997; Single \& Muller, 1999a).

The growth in electronic communication is providing new opportunities for the development of communities. New definitions of community recognize the Internet's ability to connect persons based on shared values and interests, independent of location (Palloff \& Pratt, 1999). E-communities emerge when individuals come together on an electronic discussion list (e-list) or web-based bulletin board around a common interest or characteristic and when the group takes on a life of its own and becomes more than the sum of the individuals and individual relationships that have entered the group.

This article examines several deliberately created opportunities for developing e-communities around issues affecting women in the engineering and science fields. In this current study, we examine elists sponsored by MentorNet, a large-scale e-mentoring program, which matches women students in the engineering and science fields with industry professionals. We have identified several variables associated with the emergence of e-communities so we can extend the benefits of such opportunities to increasing numbers of women engineering and science students and professionals.

One reason for fostering the development of community among women in the engineering and science fields is to contribute to increasing the representation of women in traditionally male dominated fields. Women remain underrepresented in the physical sciences and severely underrepresented in engineering fields. In engineering, where the gender discrepancy is the largest, women earned just $18.6 \%$ of the undergraduate, $20.3 \%$ of the master's, and $12.3 \%$ of the doctoral degrees in 1998 (American Association of Engineering Societies, 1998). Because of workplace climate and historical barriers, women engineers in the workforce are even scarcer - representing less than $10 \%$ of the engineering workforce (National Science Board, 1998).

The underrepresentation of women, at the professional and postsecondary level, can be attributed to socialization in a culture where engineers and scientists are typically seen as male, to a dearth of women role models, and to unfavorable educational climates (Char, 1997; Leslie, McClure, \& Oaxaca, 1998; Yauch, 1999). At the postsecondary level, women tend to enter technical and scientific fields at lower rates than their male counterparts. In 1996, 2.4\% of women first-year undergraduates aspired to be engineers compared with $12.8 \%$ of their male counterparts and many studies suggest that women drop out of these programs at higher rates (Astin, 1998; Strenta, Elliott, Adair, Matier, \& Scott; Takahira, Goodings, \& Byrnes, 1998). In the physical and life sciences, women's participation is higher at the undergraduate level, with women earning $43 \%$ of all the physical and 
life and $36 \%$ of the physical science baccalaureate degrees, their participation decreases at the graduate level, where they earn $30 \%$ of all physical and life science doctoral degrees and $23 \%$ of all physical science doctoral degrees (National Science Board, 1998).

Women enter undergraduate engineering and science programs with similar levels of motivation, ability, academic preparation, and support as their male counterparts (Hawks \& Spade, 1998; Felder, Felder, Mauney, Hamrin, \& Dietz, 1995); thus, the gender gap does not appear to stem from cognitive or motivational differences. Competitive and unwelcoming classroom environments, more common in engineering and science courses, deter women from entering or persisting in these fields (Crawford \& MacLeod, 1990; Meinholt \& Murray, 1999; Tobias, 1990). One result is that women engineering students' levels of academic self-confidence and self-esteem dip dramatically during their first year of college (Brainard \& Carlin, 1998). In addition, women students are excluded too often from informal networking, mentoring relationships, and research opportunities (Drew \& Work, 1998; Hall \& Sandler, 1982). Also lacking in undergraduate and graduate women students' educational experiences are opportunities to interact with engineers who are working in the industrial workplace (those around colleges and universities are typically academic engineers). This means a dearth of role models and less understanding of what engineers do.

Based on the increased need for engineers in the workforce, the stagnation or decline of men enrolling in engineering programs, and the persistent underrepresentation of women in these fields, a current and projected shortfall exists in the engineering and technical workforce (Astin, 1998; Gaudin, 1999). Women remain an untapped labor source that could help address the shortfall. The efforts of industry and government have fueled a nation-wide effort to increase the retention of women in engineering studies (Brainard \& Metz, 1996). To retain women in science and engineering, colleges have established Women in Science and Engineering (WISE) programs. During the past 20 years, the number of WISE programs has increased substantially. Some evidence suggests that the number of programs and events offered for women are positively related to the percentage of women earning bachelors degrees in these fields (Wadsworth, 1992). Women's programs support women students by offering mentoring opportunities, access to women role models, group meetings and events (Brainard \& Ailes-Sengers, 1994; Muller \& Pavone, 1997). These programs allow female students to receive psychosocial support and to learn coping strategies relevant to pursuing an education in a male dominated field; mentoring is an important component of these programs as it helps socialize students into a particular field of study (Boyle \& Boice, 1998a). WISE programs allow women students to increase their knowledge about a field and to learn about the opportunities available to them, which can result in higher retention rates (Cunningham, 1996; Cunningham, Pavone, \& Muller, 1996).

WISE programs often call on women professionals working in the technical and scientific workforce to serve as role models and mentors. Through the provision of support services to women students, WISE programs may provide benefits to women engineers and scientists. Professionals serving as mentors report that they experience increased self-confidence, increased commitment to their field, and the opportunities to engage in self-reflection and assessment of their own careers paths and professional development (Boyle \& Boice, 1998b; Kram, 1983). Through serving as mentors, more experienced professionals have revitalized their own careers (Boice, 1986). These beneficial, albeit unintended, consequences may serve an important role in the lives of the women professionals. Statistics show that the number of women receiving postsecondary degrees are not repre- 
sented in the workforce; nearly $50 \%$ of the women who do not pursue graduate work exit from the technical and scientific workforce after earning an undergraduate degree in engineering or science (Alper, 1993; National Science Foundation, 1996). By soliciting professionals to serve as mentors, these programs may be helping to keep women in the technical and scientific workforce.

Electronic communications allow support programs, such as those offered by WISE programs, to connect more women students with professionals, since these connections can transcend organizational barriers, geographical distances, and scheduling difficulties. MentorNet, the National Electronic Industrial Mentoring Network for Women in Engineering and Science, is an example of such a program. MentorNet uses technology to support women in the engineering and science fields (Muller, 1997). The program pairs undergraduate and graduate women studying engineering and related sciences with volunteer professionals in industry for a year-long structured mentoring relationship conducted via email. MentorNet offers web-based applications, an automated matching process, and a structured mentoring format, building on the successful elements of structured face-to-face mentoring programs (Boyle \& Boice, 1998b; Single \& Muller, 1999a).

In addition to offering one-to-one e-mentoring opportunities, MentorNet experimented in 199899 with promoting interaction among students and professionals by sponsoring informal e-lists. We decided to sponsor informal e-lists because the student interest in MentorNet's one-on-one e-mentoring program exceeded the capabilities for matching students with mentors. To provide an opportunity for the unmatched students to interact with professionals, we invited them to subscribe to one, or several, e-lists. All the professionals, whether matched in one-on-one relationships or not, also were encouraged to participate in the e-lists.

Some of the MentorNet e-lists were very successful, emerging into communities. In contrast, other e-lists generated little or no activity. In this article we compare the characteristics of the emergent e-communities with those of the less successful e-lists. The goals of this study were to identify features of successful e-communities, so they can be reproduced in the future, and to gain insight into the needs of the populations that participated in the e-communities.

\section{METHODS}

\section{Participants}

All participants had signed up with MentorNet during the 1998-1999 academic year. We invited 693 industry professionals, who had volunteered as mentors, to subscribe to the e-lists. Of the professionals, 539 had already been paired in one-on-one e-mentoring relationships with students, and the remaining 154 had not been paired. We also invited 434 students, who had not been matched in mentoring relationships, to subscribe to these e-lists.

\section{Procedure}

MentorNet staff sent an email message to all those invited to subscribe. The email message included directions on how to subscribe, along with a description of the 13 e-lists. The staff generated three categories of organizing themes for the e-lists. First, we consid- 
ered topics of interest for women students and professionals in technical and scientific fields; the resultant e-lists were called "Work/Personal Balance," "Women's Issues," and "Job Search." Second, we created elists based on the educational level of students. These e-lists were open to both students and professionals and focused on, for example, issues pertinent to first-year and sophomore undergraduate students or issues pertinent to doctoral level students. Finally, we offered e-lists based on the fields of the students and the professionals, such as Computer Engineering, or Math/Physics. There were three topic-based elists, four e-lists based on educational level, and six e-lists based on fields of study. The unmoderated elists were available for a one semester-long duration, beginning in January and ending in late May of 1999. Table 1 lists the names, categories, and descriptions of the 13 e-lists.

Table 1. Electronic Discussion List Names, Categories, and Descriptions

E-list name by category

E-lists by field
Math/Physics
Chemistry
Environ./Geo.
Bioscience
Computer Engg
Engineering

E-lists by student educational level Fresh/Sophomore

Junior/Senior

Masters level

Ph.D Level

E-lists by topic Job Search

Women's Issues

Work/Personal Balance
Description

This list caters to students and mentors involved in mathematics, physics, and statistics.

This list caters to students and mentors involved in chemistry or chemical engineering.

This list caters to students and mentors involved in environmental engineering, environmental sciences, earth sciences, or geology.

This list caters to students and mentors involved in the biological sciences, biochemistry, biochemical engineering, biomedical engineering, or biotechnology.

This list caters to students and professionals in the fields of computer science or computer engineering.

This list caters to students and professionals in the field of engineering, excluding students in computer engineering, environmental engineering, biomedical engineering, biochemical engineering, or chemical engineering.

This list caters to undergraduate students in their first and second years, as well as mentors interested in mentoring undergraduate students in their first and second years

This list caters to undergraduate students in their junior and senior years, as well as mentors interested in mentoring undergraduate students in their junior and senior years.

This list caters to students pursuing a Masters' degree in science or engineering, as well as mentors interested in mentoring students pursuing a Masters' degree in science or engineering

This list caters to students pursuing a Ph.D. degree in science or engineering, as well as mentors interested in mentoring students pursuing a Ph.D. degree in science or engineering.

This list caters to students and mentors interested in a discussion about conducting a search, finding internships, resume writing, and other related issues.

This list caters to issues pertinent to women students and professionals in engineering, science, or mathematics.

This list caters to students and mentors interested in discussing issues pertaining to balancing professional life and personal life. 


\section{Analysis}

We compared the 13 e-lists by the number of subscribers, postings, topics, and the duration of the e-lists. Not everyone who subscribed actively participated in the e-list. Therefore, we defined participants as those subscribers who participated in the e-list interaction by posting at least one email message to the elist. Every email message sent to the e-lists was considered a posting, including the email messages where the participants introduced themselves. In our assessment of e-list traffic, we defined a "topic" as a discussion thread that had at least four postings. All the initial introductory messages posted to one e-list were counted as one topic; this explains why some e-lists with fewer than four postings have a recorded topic. We defined duration as the number of days email was posted to a list from the opening of the elists until the final email message posted to a list. To examine the relationships among the different variables for all 13 e-lists, we constructed a correlation matrix using Pearson's correlation coefficient. The number of postings, the number of topics, and duration, served as the primary quantitative outcome measures distinguishing the successful e-lists that emerged into e-communities.

To comparatively test how the e-lists differed, we performed analyses based on the three types of organizing categories - topics, educational level, and field. Because each category only contained a few e-lists and because we wanted to treat each e-list as a unit of analysis, we used non-parametric methods to analyze the data. Using the Kruskal-Wallis $(\underline{\mathrm{KW}})$ test as a non-parametric substitution for an analysis of variance test, we compared the three e-list categories based on the e-list variables identified earlier: number of subscribers; number of participants; number of postings; number of topics; and, duration.

In addition, we conducted a content analysis of the e-list with the highest number of postings, which also had the longest duration, in order to identify any distinguishing characteristics of an e-list that emerged into an e-community. We focused on both the content of the messages and the flow of the electronic conversation (e.g., what factors lubricated the conversation), and identified categories and themes that emerged. In accordance with constant comparative method (Glaser \& Strauss, 1967), we compared the data to the emerging categories and themes to test the hypotheses generated earlier. Content and structure were carefully scrutinized to determine whether they were consistent with the existing categories and themes or whether some modifications were needed to the current scheme. Based on this coding, we developed the generalizations about the emergence of e-communities outlined in this article.

\section{RESULTS}

\section{Demographics and Electronographics}

The number of persons who subscribed to the e-lists was counted at the end of the program year; the number of subscribers may have varied throughout the life of the e-list since the invitees could subscribe and unsubscribe during this period. Of those invited to join the e-lists (1,127 in total), 419 were subscribed at the completion of the life of the e-lists. These 419 subscribers represent $37 \%$ of those invited.

The number of subscribers per e-list ranged from 8-66, with a mean of 32.2. The e-lists with the greatest number of subscribers were the three topic-based e-lists: the Work/Personal Balance e-list, the Women's Issues e-list, and the Job Search e-list. These three 
e-lists accounted for $43 \%$ of the subscribers to all the e-lists. See Table 2 for the number and percentage of subscribers per e-list.

The 13 e-lists had 140 participants (as mentioned earlier, participants were subscribers who posted to the e-lists), comprising $33 \%$ of the total subscribers, and an average of 10.7 participants per elist. The number of participants per e-list ranged from 0-41. The topic-based e-lists had the greatest number of participants. The Work/Personal Balance e-list had 41 participants, the Women's Issues e-list had 35 participants, and the Job Search e-list had 32 participants. The e-lists focusing on the Math/Physics fields, the Chemistry fields, and the Bioscience fields all had zero participants. Professionals accounted for 73\% (102/140), of all the participants. Students accounted for 27\% (38/140). Using a z-test, the difference between the proportions of professional and student participators was significant $(\mathrm{p}<.001)$. Table 2 lists the number of professionals, students, and total participants per e-list.

The number of postings per e-list ranged from 0 to 148, with the average number of postings per e-list being equal to 30.2. The number of topics discussed per e-list ranged from 0 to 31 , with the mean number of topics equal to 4.5. The duration of the e-lists ranged from 0 to 112 days. The average duration of all the e-lists was 29.9 days. The three topic-

Table 2. Demographics, Electronographics, and Variables of the MentorNet Electronic Discussion Lists

\begin{tabular}{|c|c|c|c|c|c|c|c|c|}
\hline \multirow[b]{2}{*}{ E-list name by category } & \multicolumn{2}{|c|}{ Subscribers } & \multicolumn{3}{|c|}{ Participants } & \multirow{2}{*}{$\begin{array}{c}\text { No. of } \\
\text { postings }\end{array}$} & \multirow{2}{*}{$\begin{array}{l}\text { No. of } \\
\text { topics }\end{array}$} & \multirow{2}{*}{$\begin{array}{c}\text { Duration } \\
\text { of list in } \\
\text { days }\end{array}$} \\
\hline & No. & $\%$ & Total & Professionals & Students & & & \\
\hline \multicolumn{9}{|l|}{ E-lists by Field } \\
\hline Math/Physics & 8 & 2 & 0 & 0 & 0 & 0 & 0 & 0 \\
\hline Chemistry & 11 & 3 & 3 & 2 & 1 & 4 & 1 & 7 \\
\hline Environ./Geo. & 12 & 3 & 8 & 4 & 4 & 11 & 2 & 7 \\
\hline Bioscience & 37 & 9 & 0 & 0 & 0 & 0 & 0 & 0 \\
\hline Computer eng. & 40 & 10 & 9 & 8 & 1 & 13 & 3 & 13 \\
\hline Engineering & 26 & 6 & 0 & 0 & 0 & 0 & 0 & 0 \\
\hline Total & 134 & 33 & 20 & 14 & 6 & 28 & 6 & 27 \\
\hline Mean & 22.3 & 5.5 & 3.3 & 2.3 & 1 & 4.7 & 1 & 4.5 \\
\hline \multicolumn{9}{|c|}{ E-lists by student educational level } \\
\hline Frosh/Sophomore & 27 & 6 & 1 & 1 & 0 & 1 & 1 & 1 \\
\hline Junior/Senior & 30 & 7 & 3 & 2 & 1 & 11 & 2 & 17 \\
\hline Masters Level & 20 & 5 & 2 & 1 & 1 & 2 & 1 & 2 \\
\hline Ph.D. Level & 27 & 6 & 6 & 3 & 3 & 9 & 2 & 41 \\
\hline Total & 104 & 24 & 12 & 7 & 5 & 23 & 6 & 61 \\
\hline Mean & 26 & & 3 & 1.8 & 1.3 & 5.8 & 1.5 & 15.3 \\
\hline \multicolumn{9}{|l|}{ E-lists by topic } \\
\hline Job Search & 55 & 13 & 32 & 12 & 20 & 84 & 5 & 99 \\
\hline Women's Issues & 60 & 14 & 35 & 30 & 5 & 148 & 11 & 112 \\
\hline Work/personal balance & 66 & 16 & 41 & 39 & 2 & 110 & 31 & 90 \\
\hline Total & 181 & 43 & 108 & 81 & 27 & 342 & 47 & 301 \\
\hline Mean & 60.3 & - & 36 & 27 & 9 & 114 & 15.7 & 100.3 \\
\hline Overall Total & 419 & 100 & 140 & 102 & 38 & 393 & 59 & 389 \\
\hline Overall Mean & 32.2 & - & 10.7 & 7.8 & 2.9 & 30.2 & 4.5 & 29.9 \\
\hline Overall Range & $8-66$ & - & $0-41$ & $0-39$ & $0-20$ & $0-148$ & $0-31$ & $0-112$ \\
\hline
\end{tabular}


based e-lists had the largest number of postings, topics, and the longest duration of all the e-lists. See Table 2 for the number of postings, topics, and duration associated with each of the 13 e-lists.

\section{Relationships Among E-list Variables}

Using the Person correlation coefficient, there were significant positive relationships among the number of postings per e-list, the number of topics per e-list, and the duration of the e-lists, as may be expected since these variables indicate the relationship between e-list traffic and duration. The number of e-list subscribers and the total number of participants were positively related to the number of postings, the number of topics, and the duration of the e-lists. The strong intercorrelations among the participants and the activity of the e-list can mostly be attributed to the number of professionals who participated in the elists. The number of professionals as participants was related to the number of postings per e-list, the number of topics, and the duration of the e-lists. The number of student participants was not related to elist traffic or e-list duration. See Table 3 for the correlation matrix.

\section{List Variables by E-list Category}

The three topic-based lists were distinguished by having more activity and a longer duration compared with the other lists. The topic-based lists had significantly higher numbers of subscribers $[\underline{\mathrm{KW}}$ asymptotic Chi-Square $(2,13)=6.69, \underline{p}<.05]$ and professional participants $[\underline{\mathrm{KW}}(2,13)=6.60, \underline{\mathrm{p}}<.05]$ compared with the lists by educational level and the field-specific lists. The topic-based lists had an average of 60.3 subscribers and 27 professionals as participants. In contrast, the lists by educational level had an average of 26 subscribers and 1.8 professionals as participants and the field-specific lists had an average of 22.3 subscribers and 2.3 professionals as participants. The number of student participants was not significantly different among the three categories of e-lists.

The topic-based e-lists also had a significantly higher number of postings $[\underline{\mathrm{KW}}(2,13)=6.69, \underline{\mathrm{p}}<$ $.05]$, number of topics $[\underline{\mathrm{KW}}(2,13)=7.10, \underline{\mathrm{p}}<.05]$, and longer duration $[\underline{\mathrm{KW}}(2,13)=7.52, \underline{\mathrm{p}}<.05]$ compared with the field-specific e-lists and educational level e-lists. The topic-based e-lists had on average 114 postings, 15.7 topics, and lasted for 100.3 days. On average, the e-lists by educational level had 5.8 postings, 1.5 topics, and lasted for 15.3

Table 3. Intercorrelations among Electronic Discussion List Variables

Subscribers Participants Professionals Students Postings Topics Duration

\begin{tabular}{|c|c|c|c|c|c|c|}
\hline & & & & & & \\
\hline Subscribers & $0.86^{* *}$ & $\begin{array}{l}0.83^{* * *} \\
0.94 * * *\end{array}$ & 0.44 & $0.84 * * *$ & $0.73 * *$ & $0.84 * * *$ \\
\hline Participants & & & $0.58 *$ & $0.95^{* * *}$ & $0.83 * *$ & $0.95^{* * *}$ \\
\hline Professionals as Participants & & & 0.26 & $0.92 * * *$ & $0.93 * * *$ & $0.85^{* * *}$ \\
\hline Student Participants & & & & 0.50 & 0.12 & 0.66 \\
\hline Postings & & & & & $0.75^{* *}$ & $0.95 * * *$ \\
\hline Topics & & & & & & $0.69 * *$ \\
\hline Duration & & & & & & - \\
\hline
\end{tabular}

Note. Each e-list serves as a unit of analysis, therefore, $\mathrm{n}=13$.

$* \mathrm{p}<.05 . * * \mathrm{p}<.001 . * * * \mathrm{p}<.0001$. 
days; the field-specific e-lists had on average 4.7 postings, 1 topic, and lasted for 4.5 days. See Figure 1 for a graph of the e-list variables by category.

\section{Content Analyses}

We conducted further analyses of the e-lists to examine what distinguished the e-lists that endured compared with those that had not. Eight of the thirteen e-lists lasted for two weeks or less. Of these eight e-lists, three did not have any postings; the remaining five e-lists had postings, yet all e-list activity ceased within 14 days. In the case of these five e-lists, the participants in these e-lists posted introductions of themselves, but the initial introductory postings did not generated comments or additional postings from other subscribers.

To understand better why some of the e-lists emerged into e-communities, we conducted an indepth analysis of the e-list with the largest number of postings, the Women's Concerns e-list. The description for this topic-based e-list stated: "This list caters to issues pertinent to women students and professionals in engineering, science, or mathematics."

Conducting this analysis helped us identify several noteworthy characteristics of the emergent ecommunity. First, the postings began with lengthy self-introductions by professional and student participants. The introductory messages included descriptions of specifics about life experiences, which fostered comments from other e-list subscribers and stimulated a number of simultaneous threaded discussions. In contrast to the eight e-lists that lasted less than two weeks, the introductions to this e-list motivated other e-list subscribers to comment on the information revealed in the introduction and create cross-traffic among e-list subscribers.

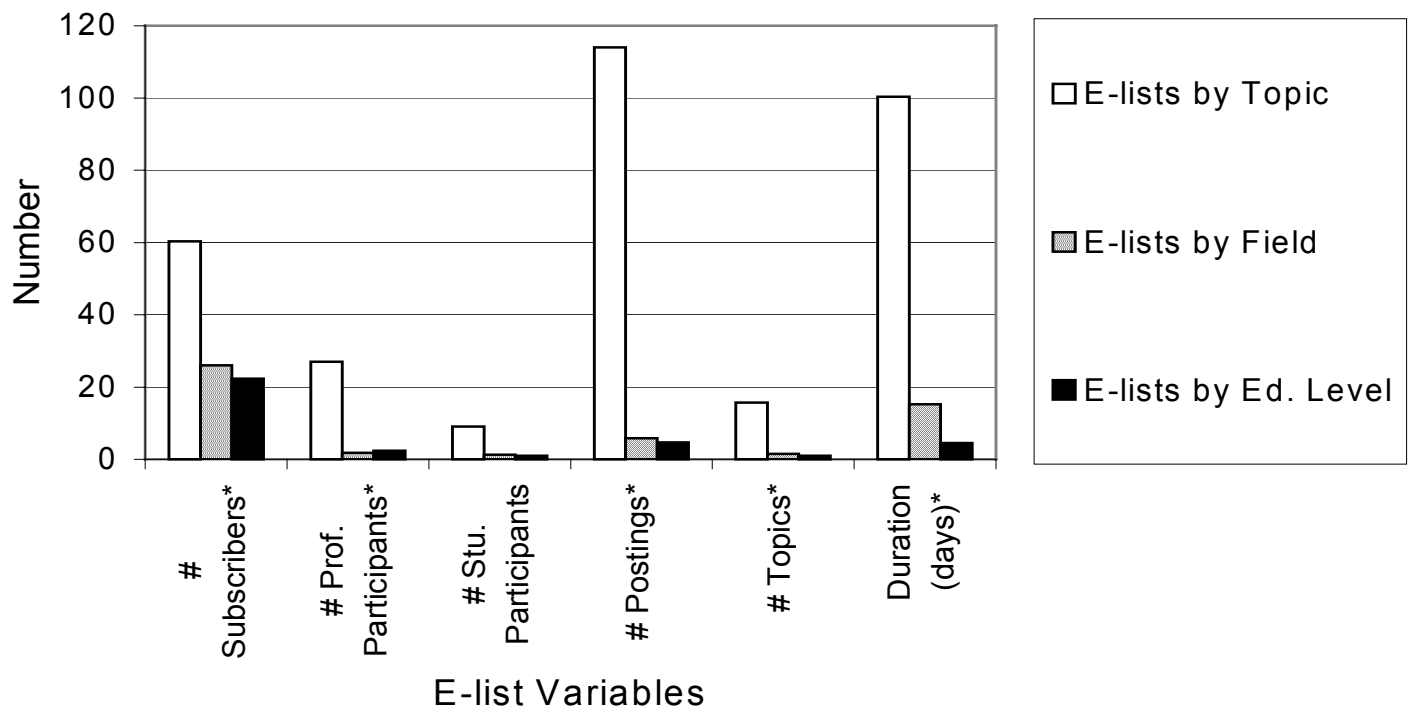

Figure 1. Comparison of the e-list variables by three categories.

(*Using the Kruskal-Wallis test, the 3 e-list categories differ significantly on this variable at the $\mathrm{p}<.05$ level.) 
Second, the e-list sustained a number of simultaneous discussion threads. After the introductory period, which lasted approximately two weeks, an average of three to four discussion threads co-existed for the remainder of the electronic group discussion. The long self-introductions mentioned above quickly spawned several different topics of discussion. Through the sharing of personal experiences and the posting of additional discussion topics, the participants maintained these simultaneous threads. By fostering a variety of active discussions, the e-list catered to the needs of a wide range of subscribers. This characteristic of the e-list allowed the subscribers to become involved with and post to the threaded discussions they found personally and professionally relevant and to disregard the threaded discussions of less interest to them.

Third, one of the topics that lasted throughout the e-list was a threaded discussion we called "life experiences". This threaded discussion was generated based on the self-introductions of the participants. The postings related to this threaded discussion contained a broad range of issues and, in numerous cases, contained very personal information about being a woman in a male dominated profession. The sharing of such insights allowed the other participants to identify with, comment on, and contribute to, the discussion. For example, the following comment by a woman professional spurred a spirited discussion thread about how discrimination has changed:

But now, discrimination is more subtle and more individual. An older colleague will occasionally "put me in my place" with an act of courtesy - offering me, but not the men around me, a seat or assistance with a heavy box.

Another comment by a woman professional fueled a discussion thread about the lack of women role models and the various ways this handicaps up and coming women engineers:

I am working my way into upper management, and have no role models... as a field engineer, I wore jeans and a nice shirt most of the time. As a manager, I have to dress up, but don't know how!! Well, I'm doing better now, but it is hard not having someone to emulate.

A fourth distinguishing characteristic of this e-community was that the e-list participants took the initiative to post messages that could be developed into longer threaded discussions. Some of these were related to national events or policies, such as a posting from a professional referring to a report from MIT about gender discrimination in the faculty ranks:

There was an article about the report in today's NY Times, so it can be viewed at www.nytimes.com and they also give the URL for the actual report.

\section{The great thing about this is that the MIT administration welcomes the report and seems very} interested to do something about it

In addition, e-list participants seeded conversations by posting questions. Some of the questions sought information, some sought advice, while other questions were more philosophical. Occasionally these questions received no response. Most often, however, other participants with more experience or advice responded. An example of a philosophical type of question was posed in light of the scandal involving President Clinton and Monica Lewinsky. A student asked: 
So, I wanted your opinion of Monica Lewinsky. Our professor applauded her for being a feminist and changing the face of feminism. However, a few of us in the discussion decided that we couldn't respect her because the decisions she made were very poor. Our professor insisted that the issue today is that society is pitting women against each other by condemning Monica.

This question prompted a lengthy exchange about who was to bear the brunt of the blame for the scandal and raised various issues related to personal and societal views on relationships, gender differences relating to power, and defining maturity. Perhaps more importantly, by having a forum to post questions where she could safely present her doubts, the student was able to voice, and have validated, her own perspectives that contradicted those of the professor.

Finally, we observed that the interactions in the e-list continued most robustly when the discussion prompted, embraced, and validated opposing opinions or perspectives. For example, occasionally a male professional joined an existing conversation and provided a slightly different perspective that redirected the conversation:

[Male Professional]: Some posts have discussed the "invisibility" of women at meetings, where their ideas are ignored or stolen by men at the meetings. Do those of you who have experienced this feel that the cause was gender bias or gender-based differences in communication style? Deborah Tannen in her books says that men tend to see communications as a competition, and women tend to see it as a means of reaching a consensus. The communication style differences are great enough that they could have the same appearance and effect as overt bias. The distinction is important because, although one can't do much about another person's bias, one can narrow a communication gap by learning about differences in communication style.

[Female Professional's Response]: He makes a very good point. For the longest time, I was challenged by this issue. I took personally how I was being treated. Once I was made aware of the "style" difference through a communications training seminar I attended, I tested it out and things seem to be much better now.

Everyone participating in this e-list was sympathetic to the issues women face while pursuing careers in male dominated professions, therefore, the diverse perspectives served to enliven, enrich and energize the conversations. Even with differing opinions, the e-list continued to be a safe and supportive environment.

\section{DISCUSSION}

The e-lists were set up to provide support to students who had signed up for MentorNet, but who could not be matched in one-to-one e-mentoring relationships because of the large number of students that signed up. Participating in the e-lists provided students with the opportunity to ask advice from, or express reservations about what they are learning in school with, an interested, yet impartial, group of professionals. The e-lists also seemed to play an important role for the women professionals in technical and scientific fields, and to fulfill their need to interact in a safe and comfortable setting with other women professional engineers and scientists, and sympathetic men. The number of professionals 
who participated in the e-lists was a predictive factor in whether an e-list emerged into a lively and vibrant e-community. This is perhaps the most interesting finding of this project - provided with the forum, women professionals capitalized on the opportunity to interact with other women professionals in the engineering and science fields. The women professionals, who are even more underrepresented than their student counterparts, may desire connections, support, and advice from other women and likeminded men.

The implications of our findings may help others who are interested in establishing communities in cyberspace. From the quantitative analyses and content analyses of the thirteen e-lists, we found that the more successful and active e-lists, those that emerged into e-communities, shared some specific traits. The first finding was that the e-communities had a substantial number of subscribers, on average about 60 subscribers. The topic-based e-lists drew those interested in issues that cut across fields and educational levels, such as women's concerns and job searching. Those who subscribed to these e-lists already shared similar interests and needs. Perhaps it is not enough to share an affiliation with a specific field or educational level to generate and sustain discussions. On the other hand, the educational level and fieldspecific e-lists may not have had a large enough population to sustain threaded discussions for very long, so this conclusion remains to be tested. In addition, the topics chosen for the e-lists may account for the lower participation rate of the students, as two of the three organizing themes for the e-lists may have been more engaging to the professionals. The e-list that focused on job searching, and that emerged into our definition of an e-community, had a greater number of student participants than professional participants. In the future, e-lists that focus on topics specific to students such as job searching, career options for biology students, and societal benefits and future trends in engineering, may draw more student participants and participation. Nonetheless, one implication for the establishment of ecommunities is that the issue or topic for an e-list needs to be able to draw a substantial number of subscribers.

A second implication of this study is that either informally or formally, it seems beneficial for elists to have moderators or facilitators. Why? For an e-list to emerge into an e-community, new topics need to be raised periodically. In this examination of the MentorNet sponsored e-lists, we found that several of the professionals took it upon themselves to serve informally as e-list facilitators. These professionals activated the e-list by periodically introducing new, broad-based topics to the e-lists, and more often than not, these topics developed into a threaded discussion, drawing others into the interaction. The new topics can be raised either explicitly, in the form of a question or a plea for advice, or implicitly, as part of a larger description or story. In addition, to get the e-lists off to a successful start, these facilitators should be cognizant of the importance of self-introductions that are full and lengthy. Therefore, when the facilitators are inviting potential members to subscribe, they may provide coaching on professional and/or personal characteristics that could be disclosed during the introductory messages. The e-list facilitator also may want to be aware that the e-list will continue most robustly when a handful of threaded discussion e-lists are developing simultaneously. Therefore, the facilitator will want to seed discussion topics not when there are few or no postings, but when he or she notices that only one or two threaded discussions are active.

The final implication from this study illustrates a crucial factor in the development of ecommunities - the participants need to perceive the e-lists as safe places where they can voice their concerns and opinions. A certain level of comfort and trust emerged within the e-communities reported in this study. The participants seemed to realize that these were 
safe and self-contained e-lists where they could, and did, share personal experiences. At no point on any of these e-lists was anyone flamed or insulted, a reason women engineers and computer scientists cited for opting out of many traditional e-lists and instead joining a women's only electronic forum (Winter \& Huff, 1996). The participants also seemed to recognize that their self-disclosure would be validated and treated with respect, even if others had a differing perspective on the issues. Consequently, the e-list participants could freely contribute diverse and divergent perspectives; therefore, there existed a variety of viewpoints to stimulate conversation. Based on our analyses, we found that disagreement among those in a diverse audience (who share mutual interests) creates a more robust discussion and an active e-list. The diverse perspectives foster active discussion within a topic, and within an e-list.

Our examination of the MentorNet e-lists leads us to four primary conclusions. First, the e-list themes need to be inclusive enough to attract a sizable number of subscribers who share common interests, concerns, or experiences. Topic-based organization may be successful because the purpose and focus of the e-list are inherently defined. Second, for an e-list to emerge into an e-community, at least some of the participants need to serve as facilitators, either informally or formally. Third, e-communities emerge where participants feel free to express their opinions and personal experiences, implying that the communities foster trust, respect, and embrace diverse perspectives among the participants. Finally, professional women engineers and scientists may be in need of additional opportunities for professional and social support, as witnessed by their participation in the e-lists and some of their proactive comments to this effect. Perhaps as we are focusing our efforts on schoolgirls and college-aged women, we should not forget their predecessors who are still paving the way.

\section{REFERENCES}

Alper, J. (1993). The pipeline is leading women all the way along. Science, 260, 409-411. American Association of Engineering Societies. (1998). Engineering \& technology degrees. Washington, DC: Author.

Astin, A. W. (1998). The changing American college student: Thirty year trends, 1966-1996. The Review of Higher Education, 21, 115-135.

Bennett, D. T. (1997). Tele-mentoring young women in science, engineering, and computing. In S. S. Metz (Ed.) Proceedings of the Women in Engineering Conference (pp. 271-276). Hoboken, NJ: Stevens Institute of Technology.

Boice, R. (1986). Faculty development via field programs for middle-aged, disillusioned faculty. Research in Higher Education, 25, 115-135.

Boyle, P., \& Boice, R. (1998a). Best practices for enculturation: Collegiality, mentoring, and coaching. In M. S. Anderson (Ed.), New directions in higher education, 101. San Francisco: Jossey-Bass.

Boyle, P., \& Boice, R. (1998b). Systematic mentoring for new faculty teachers and graduate teaching assistants. Innovative Higher Education, 22, 157-179.

Brainard, S. G., \& Ailes-Sengers, L. (1994). Mentoring female engineering and science students: A model program at the University of Washington. Journal of Women and Minorities in Science and Engineering, 1, 123-135.

Brainard, S. G., \& Carlin, L. (1998). A six-year longitudinal study of undergraduate women in engineering and science. Journal of Engineering Education, 87, 369-375. 
Brainard, S. G., \& Metz, S. S. (1996). A U.S. partnership for change: Industry, education, government \& WEPAN. Proceedings of the World Congress of Engineering Educators and Industry Leaders, UNESCO, 3, (pp. 161-170). Paris, France.

Char, C. A. (1997). Evaluation of the electronic mentoring program: A telecommunications-based pilot program for women in science, mathematics, and engineering. A report prepared for Dartmouth College, Hanover, NH.

Crawford, M., \& MacLeod, M. (1990). Gender in the college classroom: An assessment of the "chilly climate" for women. Sex Roles, 23, 101-1222.

Cunningham, C. M. (1996). Women in Science Project evaluation. Unpublished report. Hanover, NH: Dartmouth College.

Cunningham, C. M., Pavone, M. L., \& Muller, C. B. (1996). Factors influencing women's pursuit of a college science major or science career: An evaluation of the Women in Science Project (WISP). In S. S. Metz, (Ed.), Proceedings of the Women in Engineering Conference (pp. 289-292). Hoboken, NJ: Stevens Institute of Technology.

Drew, T. L., \& Work, G. G. (1998). Gender-based differences in perception of experiences in higher education. Journal of Higher Education, 69, 542-555.

Felder, R. M., Felder, G. N., Mauney, M., Hamrin, C. E., Jr., \& Dietz, E. J. (1995). A longitudinal study of engineering student performance and retention III: Gender differences in student performance and attitudes. Journal of Engineering Education, 84, 151-163.

Gaudin, S. (1999, Nov. 22). The critical shortage of women in IT. Network World Fusion. Retrieved January 7, 2000 from the World Wide Web: http://www.nwfusion.com/news/1999/1122women.html.

Glaser, B. G., \& Strauss, A. L. (1967). The discovery of grounded theory: Strategies for qualitative research. Chicago: Aldine.

Hall, R. M., \& Sandler, B. (1982). The classroom climate: A chilly one for women? Project on the Status and Education of Women. Washington, DC: Association of American Colleges.

Hawks, B. K. \& Spade J. Z. (1998). Women and men engineering and science students: Anticipation of family and work roles. Journal of Engineering and Science Education, 87, 249-256.

Kram, K.E. (1983). Phases of the mentor relationship. Academy of Management Journal, 26, 608-25.

Leslie, L. L., McClure, G. T., \& Oaxaca, R. L. (1998). Women and minorities in science and engineering: A life sequence analysis. Journal of Higher Education, 69, 239-276.

Meinholt, C., \& Murray, S. L. (1999). Why aren't there more women engineers? Journal of Women and Minorities in Science and Engineering, 5, 239-263.

Muller, C. B. (1997). The potential of industrial "e-mentoring" as a retention strategy for women in science and engineering. Proceedings of the Annual Frontiers in Education (FIE) Conference. Retrieved on January 22, 1999 from the World Wide Web: http://fairway.ecn.purdue.edu/ fie/fie97/papers/1268.pdf

Muller, C. B., \& and Pavone, M. L. (1997). Retaining undergraduate women in science, math, and engineering: A model program. Proceedings of the Annual Frontiers in Education (FIE) Conference. Retrieved on January 28, 1999 from the World Wide Web: http://fairway.ecn.purdue.edu/ fie/fie97/papers/1267.pdf

National Science Board. (1998). Science \& engineering indicators - 1998. Arlington, VA: National Science Foundation (NSB 98-1).

Palloff, R., \& Pratt, K. (1999). Defining and redefining community. San Francisco: Jossey-Bass.

Rheingold, H. (1993). The virtual community: Homesteading on the electronic frontier. Reading, MA: Addison-Wesley.

Single, P. B. and Muller, C. B. (1999a, April). Electronic mentoring: Issues to advance research and practice. Proceedings of the Annual Meeting of the International Mentoring Association (pp. 234250). Atlanta, GA.

Single, P. B., \& Muller, C. B. (1999b). Electronic mentoring: The next frontier for supporting women's professional development. Unpublished manuscript. 
Sproull, L., \& Kiesler, S. (1992). Connections: New ways of working in the networked organization. Cambridge, MA: The MIT Press.

Steinberg, E. R. (1992). The potential of computer-based telecommunications for instruction. Journal of Computer-Based Instruction, 19, 42-46.

Strenta, A. C., Elliott, R., Adair, R., Matier, M., \& Scott, J. (1994). Choosing and leaving science in highly selective institutions. Research in Higher Education, 35, 513-547.

Takahira, S., Goodings, D. J., \& Byrnes, J. P. (1998). Retention and performance of male and female engineering students: An examination of academic and environmental variables. Journal of Engineering Education, 87, 297-304.

Tobias, S. (1990). They're not dumb, they're different: Stalking the second tier. Tucson, AZ: Research Corporation.

Wadsworth, E. M. (1992). Women's activities and women engineers: Expansions over time. Initiatives, 55(2), 59-65.

Walther, J. B. (1996). Computer-mediated communication: Impersonal, interpersonal, and hyperpersonal interaction. Communication Research, 23, 3-43.

Winter, D., \& Huff, C. W. (1996). Adapting the Internet: Comments from a women-only electronic forum. The American Sociologist, 27, 30-54.

Yauch, C. A. (1999). Majoring in engineering: A study of gender differences. Journal of Women and Minorities in Science and Engineering, 5, 183-205. 